\title{
Nonlinearity identification of Jesus Christ the King monument on the basis of modal parameters
}

\author{
Jacek Grosel $^{1, *}$, Jakub Marcinowski ${ }^{2}$, Wojciech Sawicki ${ }^{1}$, and Zbigniew Wójcicki ${ }^{1}$ \\ ${ }^{1}$ Wrocław University of Science and Technology, Faculty of Civil Engineering, 50-370 Wroclaw, \\ Wyb. Wyspianskiego 27, Poland \\ ${ }^{2}$ University of Zielona Góra, 65-417 Zielona Góra, Licealna 9, Poland
}

\begin{abstract}
The work presents an attempt to identify the nonlinearity of the structure using a simple autonomous vibration recorder. The vibrations were measured continuously for 4 days in three directions, which easily made it possible to record various load states of the structure. The analysis of the response spectra shows a change in the eigenfrequencies caused by the level of load, which is a measure of the non-linearity of the structure. The presented method is an interesting alternative to expensive multichannel visit measurements, in which the equipment is compensated by the length of measurements
\end{abstract}

\section{Introduction}

Equation of motion for a multi-degree of freedom system could be presented in a matrix form

$$
\mathbf{B} \mathbf{q}^{(2)}(\mathrm{t})+\mathbf{C} \mathbf{q}^{(1)}(\mathrm{t})+\mathbf{K} \mathbf{q}^{(0)}(\mathrm{t})=\mathbf{F}(t)
$$

where:

$\square^{(i)}$ denotes $i$-th derivative with respect to time i.e. $\mathbf{q}^{(0)}-$ vector of displacements, $\mathbf{q}^{(1)}$ vector of velocity, $\mathbf{q}^{(2)}$ - vector of acceleration,

$\mathbf{B}$ - inertia matrix, $\mathbf{C}$ - damping matrix, $\mathbf{K}$ - stiffness matrix, and $\mathbf{F}(t)$ - vector of excitation.

Applying modal transformation method to the equation (1), with assumption that damping matrix is linear combination of inertia and stiffness matrix, one obtains

$$
\{\mathbf{b}\} \mathbf{r}^{(2)}(\mathrm{t})+\{\mathbf{c}\} \mathbf{r}^{(1)}(\mathrm{t})+\{\mathbf{k}\} \mathbf{r}^{(0)}(\mathrm{t})=\mathbf{f}(t)
$$

where:

$\{\square\}$ denotes diagonal matrix. $\mathbf{r}^{(0)}-$ vector of displacements in the general coordinates base.

\footnotetext{
* Corresponding author: jacek.grosel@pwr.edu.pl
} 
Equation (2) describe motion of the system as a set of independent Single Degree of Freedom (SDOF) systems. For every SDOF system $H(\omega)$ - receptance Frequency Response Function (FRF) could be derived ( $c f$. [1]).

$$
\left.H(\omega)=1 / k_{i}\left(1-\eta_{\mathrm{i}}^{2}\right)^{2}+4 \xi_{\mathrm{i}}^{2} \eta_{\mathrm{i}}^{2}\right)^{-0,5}
$$

where:

$\square_{i}$ denotes parameter concerning $i$-th mode, $\eta=\omega / \omega_{i}, \omega_{i} i$-th eigenfrequency, $\xi-$ fraction of critical damping.

For system with well separated eigenfrequencies and excitation of white noise form Fourier Transform of measured response equals to

$$
\left.X(\omega)=H(\omega) F(\omega) \approx f_{i} / k_{i}\left(1-\eta_{\mathrm{i}}^{2}\right)^{2}+4 \xi_{\mathrm{i}}^{2} \eta_{\mathrm{i}}^{2}\right)^{-0,5}
$$

Starting form this relation $\omega_{i}$ and $\xi_{i}$ could be found by the use of nonlinear fitting, such a way for finding modal parameters are referred later as Method 1 (M1). Method 2 (M2) is commonly known as Peak-Picking method. From FRF (here FFT of response) point with maximum value $x_{\max }$ is taken, frequency of this point $\omega_{r}$ is the eigenfrequency, the frequencies $\left(\omega_{a}\right.$ and $\left.\omega_{b}\right)$ for points with value $x_{\max } / \sqrt{2}$ are determined. The fraction of critical damping is given by formula [1]:

$$
\xi_{i}=\left(\omega_{a}^{2}-\omega_{b}^{2}\right) /\left(4 \omega_{r}^{2}\right)
$$

Results obtained form M1 and M2 are compared in the next paragraphs, additionally the influence of load level on determined parameters are shown.

\section{Description of the experiment}

\subsection{Monument of the Jesus the King}

The statue of Jesus Christ the King of the Universe (cf. Fig. 1a) was erected in Świebodzin, small town in western part of Poland (cf. Fig. 1b) on the 6th of November 2010. The construction took ten years and now takes its place as the Largest Statue of Jesus Christ according to the Guinness Book of World Records [2]. It is 3 meters taller than the better known statue of Christ the Redeemer in Rio de Janeiro, standing at 30.1 meters tall without its pedestal. The figure is 33 meters high and it weighs 260 tons [3]. The head alone is $4.5 \mathrm{~m}$ tall and weighs about 3 tons. The crown is 3.5 metres in diameter and nearly $2 \mathrm{~m}$ in height and is gilded. The distance between the ends of the fingers is 26.1 meters. The statue was built on a 12 meter mound of stones and soil and along with this mound, it reaches 47.5 meters overall.

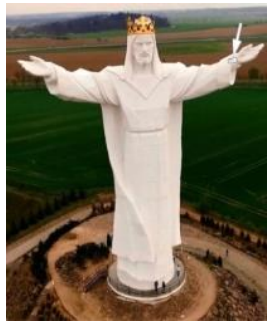

(a)

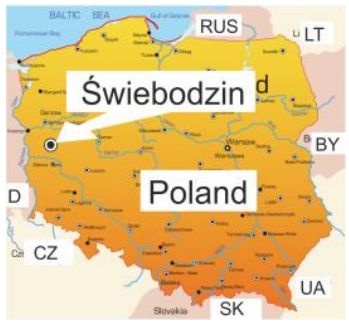

(b)

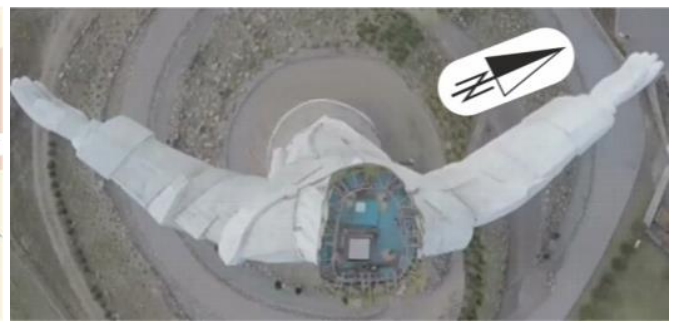

(c)

Fig. 1. Statue of Jesus Christ the King (a), location of Swiebodzin town (b), view of the monument from a bird's eye view (c) 
The statue which has foundations in a form of piles/columns connected by reinforced concrete plates placed on three levels. Piles and plates are hidden in artificial mound and all together create the pedestal of the monument. The mound himself was piled with sand, stones and clay and planted on mother land of sand and clay.

Six piles/columns were placed on the bottom, $40 \mathrm{~cm}$ thick reinforced concrete plate, located in mother land $14 \mathrm{~m}$ beneath the planned level of the statue's base. After erection of columns the mound was piled till the level of ten meters above the bottom plate. At this level the other reinforced concrete plate was made. This plate connects all columns and creates with these columns a spatial frame. On this plate six columns were placed at the same positions as their counterparts below plate. In the middle of the plate the huge, hot rolled steel bar (HEB) was erected. Together with six reinforced concrete columns it creates the upper part of the framed foundation. This upper segment of foundations was covered with sand as well and on the planned level of the statue's base the circular, reinforced concrete plate was made. This plate was the final, upper part of the foundation.

Lower segments of the statue were made of shotcrete. $2,4 \mathrm{~m}$ long segments were workshop fabricated and their walls have adopted the form of a three layer sandwich: $10 \mathrm{~cm}$ hard rockwool as the internal layer and the steel rebar as inner and outer layers covered by shotcrete. Upper segments together with the chest and the head were fabricated from glass fiber reinforced polymer attached to the steel grid. The whole statue was reinforced inside by steel, spatial truss. An additional steel truss was designed and assembled inside arms of the statue. The whole statue was painted white.

Inside the left arm the vibration recorder was installed in place indicated in Fig. 1a.

\subsection{Vibration measurement}

The measurements were carried out using the GCDC MELx2 data logger with an accelerometer inside. In the applied configuration, accelerations were measured with the sampling frequency of $512 \mathrm{~Hz}$ and resolution of $748 \mu \mathrm{m} / \mathrm{s}^{2}$. Vibrations in three directions were measured and recorded simultaneously. Direction of channel 1 was in line with the monument's hand axis, channel 3 had vertical direction and channel 2 was perpendicular to axes of channel 1 and channel 3. Vibrations were recorded in one-hour sections, measurement was performed from February 21 to 25, 2017; 94 one-hour records were saved. During the measurement, weather conditions significantly changed. According to the records from the metrological station in Zielona Gora (40 km from the monument), the average daily wind speed during the measurements time varied from 13.2 to $22.4 \mathrm{~m} / \mathrm{s}$ while the gust velocity ranged from 50.4 to $75.6 \mathrm{~m} / \mathrm{s}$. The mean square values of vibrations for horizontal directions (directions of wind) are shown in the figure below, one can observe the fluctuation of the structure response which is correlated with the level of excitation.

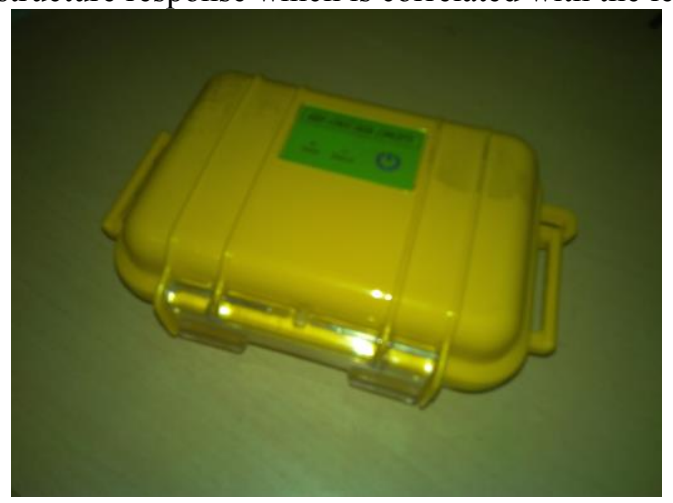

Fig. 2. Vibration recorder. 


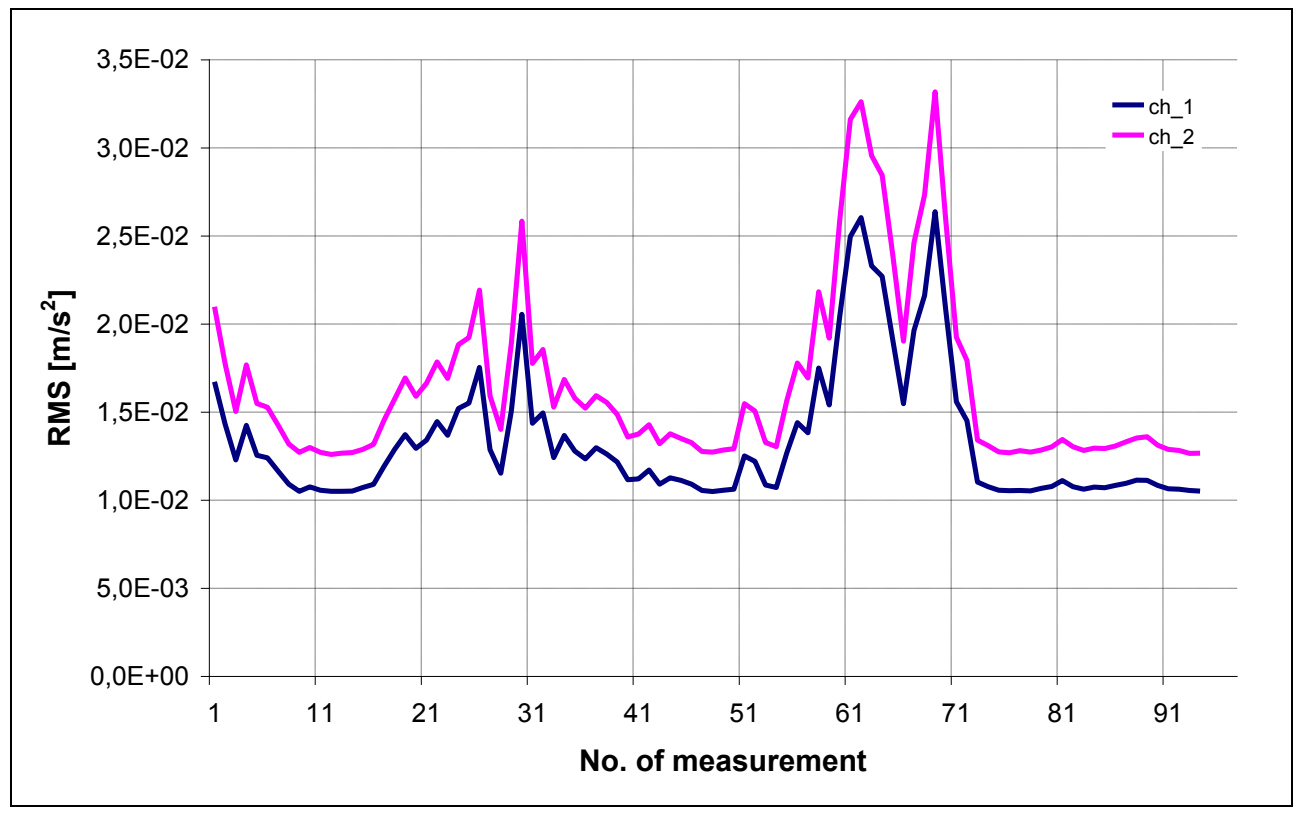

Fig. 3. RMS of recorded acceleration, channel 1 and 2.

\section{Results of the vibration analysis}

Every recorded time history was analysed with use of Fast Fourier Transform, afterwards procedure for determining modal parameters, as shown in part 1 was performed. In order to check whether the maxima on spectrographs are in fact eigenfrequencies, these maxima were compared to the previously identified eigenfrequencies [4]. Results are shown in Table 1.

Table 1. Comparison of the eigenfrequencies.

\begin{tabular}{|c|c|c|c|}
\hline & $\begin{array}{c}1^{\text {st }} \\
\text { eigenfrequency } \\
\omega_{1}\end{array}$ & $\begin{array}{c}2^{\text {nd }} \\
\text { eigenfrequency } \\
\omega_{2}\end{array}$ & $\begin{array}{c}3^{\text {rd }} \\
\text { eigenfrequency } \\
\omega_{3}\end{array}$ \\
\hline $\begin{array}{c}\text { measurement } \\
2013(\mathrm{OMA})\end{array}$ & $1,34 \mathrm{~Hz}$ & $1,44 \mathrm{~Hz}$ & $2,42 \mathrm{~Hz}$ \\
\hline $\begin{array}{c}\text { measurement } \\
2016(\mathrm{OMA})\end{array}$ & $1,33 \mathrm{~Hz}$ & $1,44 \mathrm{~Hz}$ & $2,36 \mathrm{~Hz}$ \\
\hline $\begin{array}{c}\text { measurement } \\
2017\end{array}$ & $1,31 \mathrm{~Hz}$ & $1,42 \mathrm{~Hz}$ & $2,12 \mathrm{~Hz}$ \\
\hline
\end{tabular}

Eigenfrequencies were determined on the measurement performed in 2013 and 2016, Operational Modal Analysis (OMA) was adapted and obtained eigenfrequencies were found using three axes vibration measurements recorded in five points on the structure. Differences between OMA results and eigenfrequencies found with one-point measurements vary from $1,4 \%\left(\omega_{2}\right), 2,2 \%\left(\omega_{1}\right)$ up to $12,4 \%\left(\omega_{3}\right)$. It could be stated that the first and the second eigenfrequency were found with very high accuracy.

The following figures show the identification of modal parameters for individual onehour record as well as a logarithmic type approximation of the eigenfrequency as a function 
of vibration level (RMS). For higher vibration level eigenfrequencies, both the first and the second, become smaller; two times greater vibration level results in decrease of eigenfrequency by $3,8 \%$ (for the first eigenfrequency) and by $4,7 \%$ (for the second eigenfrequency). For identification of the eigenfrequencies methods M1 (red squares and red line) and M2 (navy diamonds and navy line) give very close results and approximation, however, coefficient of determination $\left(\mathrm{R}^{2}\right)$ for method M1 is slightly higher.

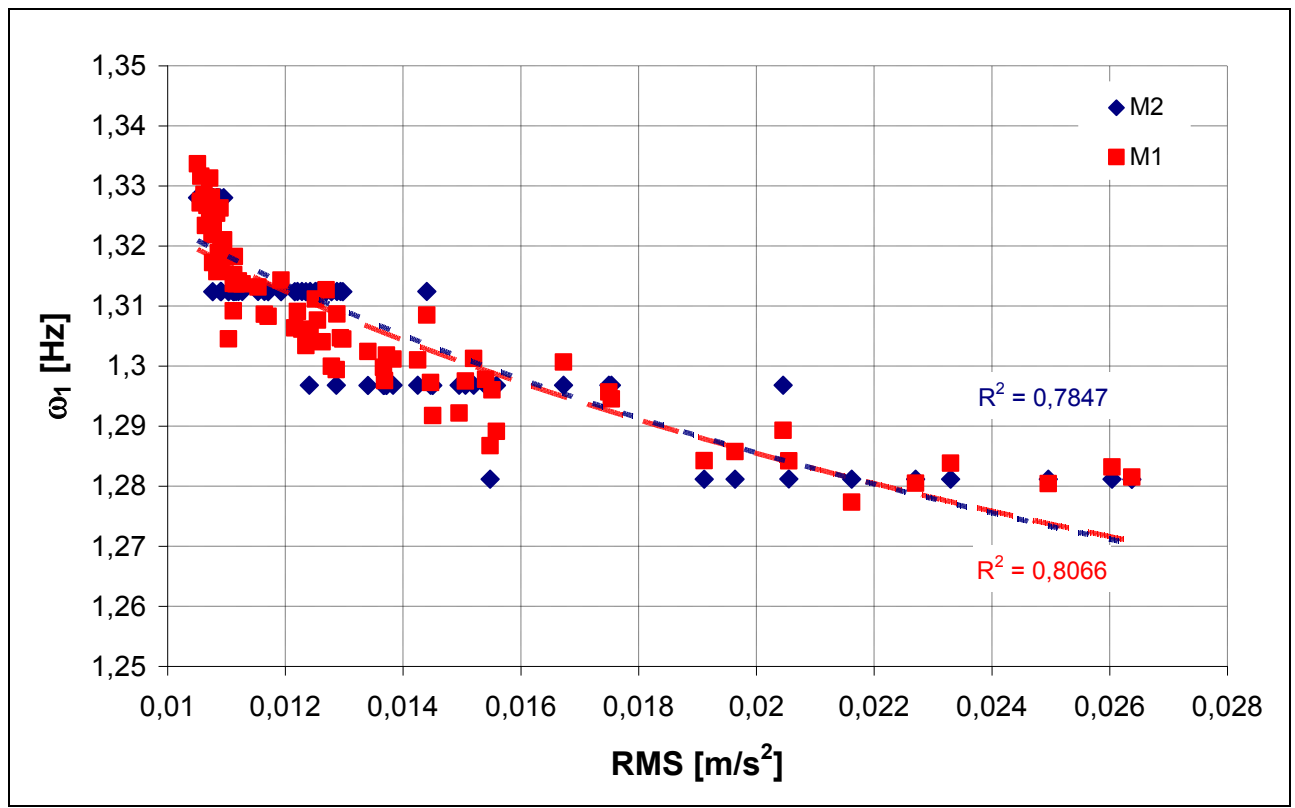

Fig. 4. The first eigenfrequency versus RMS, channel 1.

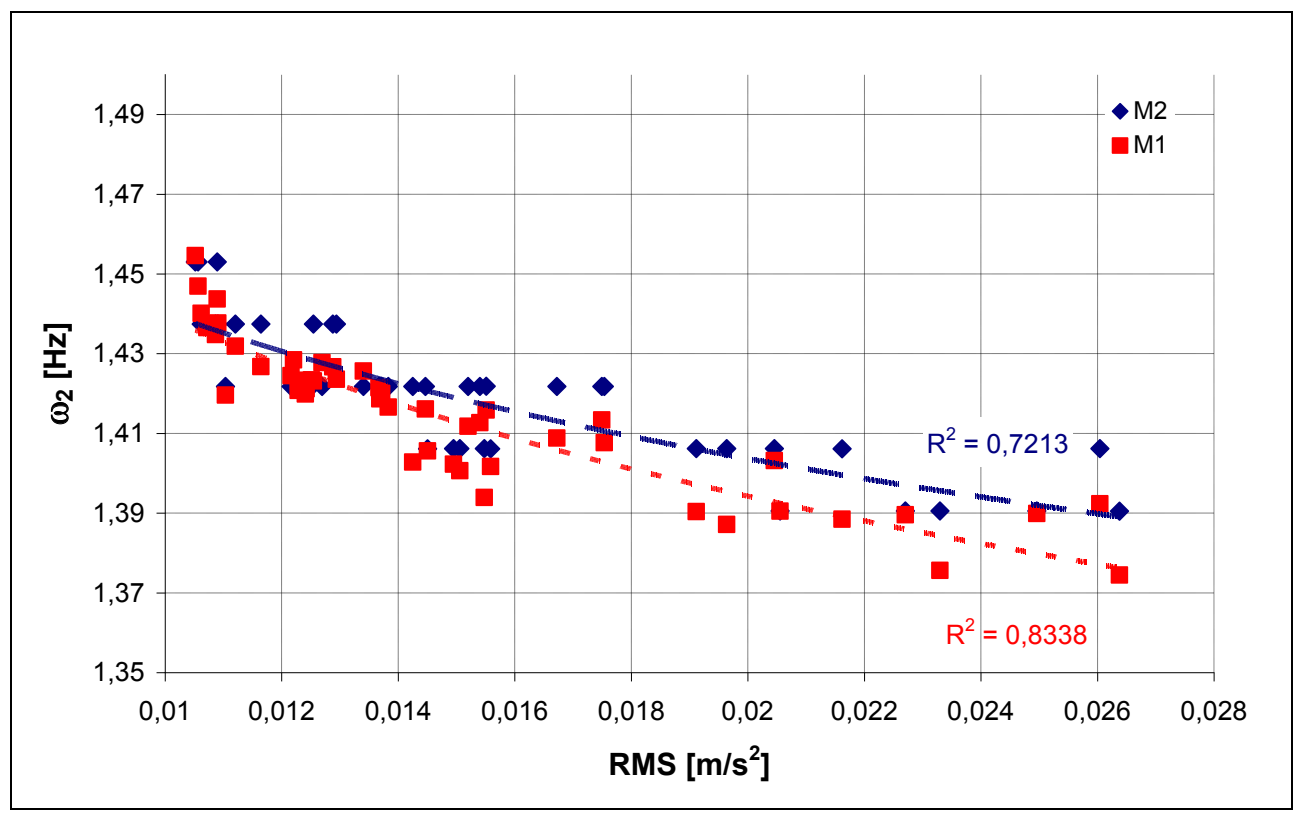

Fig. 5. The second eigenfrequency versus RMS, channel 1. 
The last figure shows the results of the critical damping fraction identification for the first eigenfrequency. In this case, the discrepancies in the results are significant and the approximation with the linear function gives much lower coefficient of determination. In case of damping identification the first method M1 gives much better results.

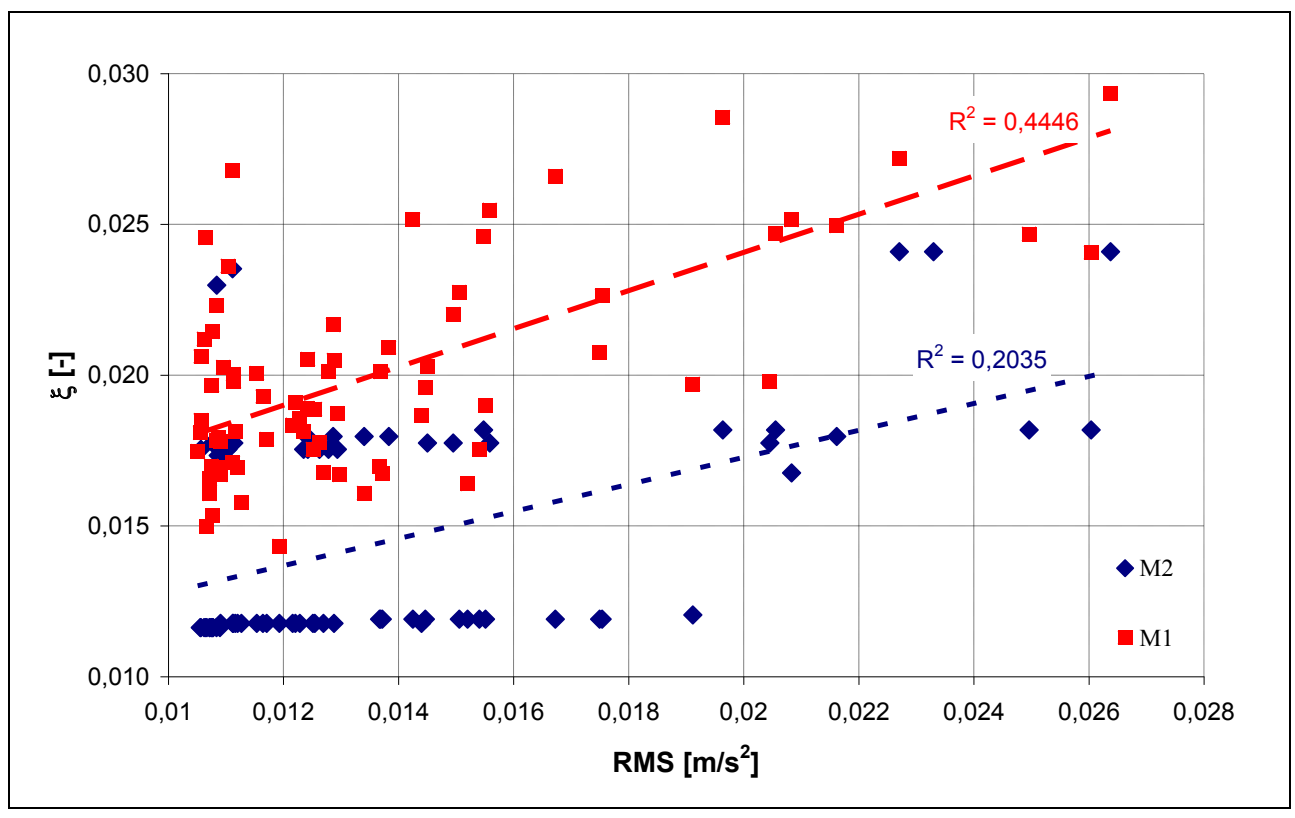

Fig. 6. The fraction of critical damping for mode 1 .

\section{Conclusions}

On the basis of the monument vibration measurement, it can be stated that: the structure has nonlinear properties, as the load increases, the eigenfrequencies decrease and the level of damping increases. The frequencies identified with the use of one measuring point coincide with the frequencies identified with the use of several measurement points in previous years. The M1 identification method is similar in accuracy with M2 for frequencies but gives better results in the identification of damping.

The use of identification method based on one measurement point, although it requires refinement, gives acceptable results from the engineer's point of view.

\section{References}

1. D. J. Ewins, Modal Testing: Theory, Practice and Application, Research Studies Press Ltd. (2000)

2. Tallest Jesus statue - Christ the King Monument sets world record. World Record Academy.com

3. Marcinowski J., Short story of a huge undertaking (in Polish), Published by University of Zielona Góra (2011)

4. Grosel J., Sawicki W., Marcinowski J., Wójcicki Z., OMA post-renovation study of the Christ the King Monument preparation for wind-load analysis, $7^{\text {th }}$ International Operational Modal Analysis Conference (2017) 